\title{
Umbilical cord ulceration-intestinal atresia syndrome
}

INSERM

\section{Source}

INSERM. (1999). Orphanet: an online rare disease and orphan drug data base. Umbilical cord ulceration-intestinal atresia syndrome. ORPHA:3405

A rare syndromic intestinal malformation characterized by ulcer formation in the umbilical cord associated with cong enital upper-intestinal atresia, typically presenting with intrauterine hemorrhaging from the ulcer site and subsequent fetal bradycardia. 